\title{
INFLUENCE OF WELD JOINT PREPARATION ON THE MECHANICAL PROPERTIES OF HIGH STRENGTH STEEL S7OOMC WELDMENTS
}

\author{
${ }^{1}$ Nikolay FERDINANDOV, ${ }^{2}$ Danail GOSPODINOV, ${ }^{3}$ Mariana ILIEVA, ${ }^{4}$ Rossen RADEV \\ University of Ruse, Ruse, Bulgaria, EU, \\ 끄ferdinandov@uni-ruse.bg, ${ }^{2}$ dgospodinov@uni-ruse.bg, ${ }^{3}$ mdilieva@uni-ruse.bg, ${ }^{4}$ rradev@uni-ruse.bg
}

https://doi.org/10.37904/metal.2021.4149

\begin{abstract}
As the tendency to lower the mass of welded constructions emerges in the last years, the use of high strength steels finds a wide range of applications in industry, namely, in reliable highly loaded welded constructions. Following the commonly accepted rules, these steels are suitable for welding. The most used welding methods for welding of high strength steels are submerged arc welding and MAG welding.

The mechanical properties of weldment of high strength steels will depend on several different welding details, such as cooling time in the range from 800 to $500{ }^{\circ} \mathrm{C}-t_{8 / 5}$, the used filler materials, welding protection, etc. Nevertheless, data on the influence of joint preparation, and specifically of the weld gap, are limited or absent. Joint preparation of high strength steels is typically performed according to EN ISO 9692-1:2013 and EN ISO 9692-2:2001. When the welding gap differs significantly from the standards recommendations, it is of great importance to research and to determine the influence of the weld gap on weldment properties and structure.

This study introduces the findings on the influence of joint preparation on some mechanical properties of high strength steel S700MC weldments produced by submerged arc welding.
\end{abstract}

Keywords: High strength steel, mechanical properties, weld structure

\section{INTRODUCTION}

The long-standing efforts for the improvement of the existing steels and the development of new steels result in the design and use of high strength steels (HSS) and ultra-high strength steels (UHSS). The need for these steels is connected to the modern requirements for constructions' optimization in terms of low construction mass combined with high strength and reliability. High strength steels and ultra-high strength steels are mainly used to produce reliable, highly loaded welded constructions working at room and lower temperatures, such as bridges, tanks, cranes, pressure vessels, industrial and civil building, pipelines, mining buildings etc. $[1,2,3,4,5]$.

The heat-treated (normalization) steels are usually with a carbon concentration of about 0.2 mass \%, whereas the thermomechanically treated (controlled rolling) steels (for instance S700MC) can contain much less carbon - from around $0.05 \%$ to $0.15 \%$. The chemical composition (lower carbon concentration, alloying elements, lower impurities' quantities) and the rolling method used for thermomechanically treated sheets of steel (controlled rolling and controlled cooling) ensure good metal deformability and reduce the layered structures and impurities bands formation $[6,7,8,9]$. These steels compared to conventional steels, have better resistance to brittle fracture as they show greater impact toughness at room and lower temperatures.

The rolling of HSS results in grain refinement [5]. Welded constructions of fine-grained steels are susceptible to notch effect and even the smallest defects can influence cracks formation and propagation. 
Fine-grained steels are characterized with good weldability using all manual, semi-automatic and automatic arc welding processes such as 111, 135, and 121. Nevertheless, welding these steels could impose three main issues, namely: 1) cold cracks formation, 2) brittleness in the grain enlargement zone, and 3) softening in the heat-affected zone [3,7].

The most advantageous structure to lower the toughness reduction can be formed when welding is performed with low linear energy and with preheating (if necessary) in the range $80 \ldots 120^{\circ} \mathrm{C}$. The temperature between the passes should not exceed $200^{\circ} \mathrm{C}$, and the most appropriate cooling time $t_{8 / 5}$ lies in the range of 10 to $25 \mathrm{~s}$.

Joint preparation of HSS is usually done according to EN ISO 9692 standard. When the root gap does not comply with the standard (i. e. when the root gap is the closing part in a weldment), it is important to research and determine the role of the root gap.

This study aims to investigate the effect of the welding gap size on the mechanical properties of but welds of high strength steel $700 \mathrm{MC}$ made by submerged arc welding.

\section{METHODOLOGY}

In the present work weldments of high strength, fine-grained steel S700MC were produced and tested. The steel was manufactured by Voestalpine Stahl GmbH, Austria, as hot-rolled sheets of $8 \mathrm{~mm}$ thickness. The chemical composition according to the manufacturer is given in Table 1.

Weldments were made using submerged arc welding with direct current and reverse polarity DC (+). The welded parts were with dimensions of 500x150x8 mm, in agreement with ISO 15614-1:2017.

Table 1 Chemical composition of 700MC (according to the manufacturer)

\begin{tabular}{|c|c|c|c|c|c|c|c|c|c|c|c|c|c|}
\hline \multicolumn{10}{|c|}{ Chemical composition, [wt \%] } \\
\hline $\mathrm{C}$ & $\mathrm{Si}$ & $\mathrm{Mn}$ & $\mathrm{P}$ & $\mathrm{S}$ & $\mathrm{Al}$ & $\mathrm{Cr}$ & $\mathrm{Ni}$ & $\mathrm{Mo}$ & $\mathrm{Cu}$ & $\mathrm{V}$ & $\mathrm{Nb}$ & $\mathrm{Ti}$ & $\mathrm{B}$ \\
\hline 0.065 & 0.049 & 1.83 & 0.006 & 0.0006 & 0.051 & 0.025 & 0.009 & 0.002 & 0.009 & 0.008 & 0.049 & 0.123 & 0.0002 \\
\hline
\end{tabular}

Joint preparation was done according to ISO 9692-2:2001 standard. The values of the root gap were different from the recommended in ISO 9692-2:2001 standard as the influence of the root gap on the mechanical properties was to be researched; thus, the welding was done using welding gaps of $0 \mathrm{~mm}, 4 \mathrm{~mm}, 6 \mathrm{~mm}$ and 8 $\mathrm{mm}$. Bevel was done mechanically at an angle of $30^{\circ}\left(60^{\circ}\right.$ total $)$ without root face.

The used filler material was a wire of G 694 M Mn3Ni1CrMo (ISO 16834:2012, or ER 100S-G according to AWS A 5.28) with a diameter of $1.2 \mathrm{~mm}$. The flux was S A AB 156 AC H5 (ISO 14174:2019).

Depending on the value of the root gap, the number of passes changed from two (at root gap of $0 \mathrm{~mm}$ ) to six (at root gap of $8 \mathrm{~mm}$ ). The current changed from $240 \mathrm{~A}$ to $270 \mathrm{~A}$ at potentials of $31 \ldots 32 \mathrm{~V}$. The welding rate was in the range of $250 \ldots 280 \mathrm{~mm} / \mathrm{min}$ for the root and $120 \ldots 180 \mathrm{~mm} / \mathrm{min}$ for the next passes. More details on the welding modes can be found in [10].

The welding was done in PA position according to EN ISO 6947:2019. The recommendation for a temperature difference of $100^{\circ} \mathrm{C}$ between the weld layers was kept [6]. Eight plates were welded - two for each root gap.

The hardness of the base metal (BM), of the heat-affect zone (HAZ), and the fusion zone (FZ) was measured using the Vickers method with a load of $1 \mathrm{~kg}$ (EN ISO 6507-1:2018).

The weldments were subjected to a tensile test. The tensile test was done according to EN ISO 6892-1:2020 and EN ISO 4136:2012. The tested pieces were standard, proportional to the original gauge length $L o=5,65 x \sqrt{ }$ So (EN ISO 6892-1:2020). The gauge length agreed with EN ISO 4136:2020. The dimensions of 
the tested specimens were as follows: a thickness of $8 \mathrm{~mm}$ (equal to the thickness of the steel sheet); a width of $25 \mathrm{~mm}$; a gauge length of $80 \mathrm{~mm}$.

After tensile testing specimens with welding gaps of 4,6 and $8 \mathrm{~mm}$ were etched to reveal their macrostructure and to localise the place of fracture. The used solution contained $20.3 \mathrm{~g} \mathrm{FeCl}_{3}, 12.5 \mathrm{ml} \mathrm{HCl}$ and $\mathrm{dH}_{2} \mathrm{O}$ up to $200 \mathrm{ml}$.

Impact toughness was performed according to EN ISO 148-1:2015. The weldments impact toughness was determined using standard specimens with a V-shaped notch. The specimens' width was $10 \mathrm{~mm}$, and the thickness was $8 \mathrm{~mm}$, equal to that of the steel sheet. The test was performed at a temperature of $-40{ }^{\circ} \mathrm{C}$. The zones where the notch was made were chosen after hardness and tensile testing.

\section{RESULTS AND DISCUSSION}

\subsection{Hardness test}

Figure 1 shows the measured hardness values of the weldments with different welding gap. There is a concordance between the measured here hardness values and the cited in the specialized literature $[6,10,11]$. The highest hardness was measured in the base metal, while the heat-affected zone was characterized by the lowest hardness.

The juxtaposition of the hardness values of the weldments with a root gap and without root gap in Figure 1 depicted a tendency towards hardness increase in the heat-affected zone; meanwhile, the hardness of the fusion zone (weld metal) was not affected by the absence or presence of a welding gap. This hardness distribution is reasonable as the fusion zone hardness is mainly influenced by the filler material and the hardness of the heat-affected zone depends on the thermal cycle $t_{8 / 5}$.

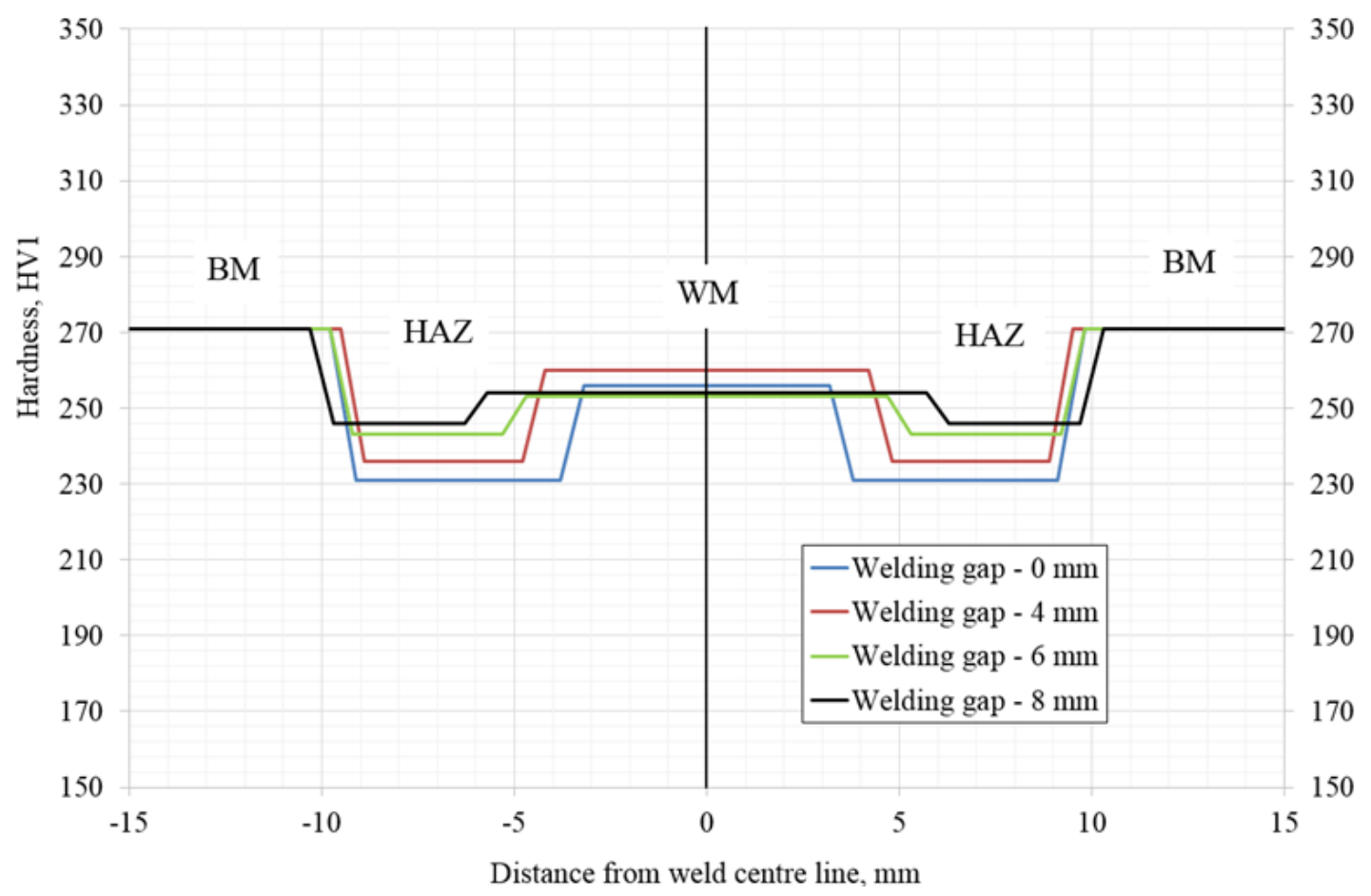

Figure 1 Influence of the weld gap on the dimensions and hardness of the different zones in the weldments 
Figure 1 demonstrates the fact that the differences in welding gap influenced in a bigger extend the dimensions of the different zones in the weldments than their hardness. The increase in the root gap led to an increase in the dimensions of the fusion zone and to a decrease in the dimensions of the heat-affected zone.

\subsection{Tensile test}

Table 2 and Table 3 represent the results from the tensile test. The given values are the averages of the testing of three specimens. Table 2 shows the mechanical properties of the steel in a delivery state. The values from Table 2 were used to find their change (in per cent) after welding and tensile testing, as it is shown in Table 3.

Table 2 Tensile testing results of the base metal in a delivery state

\begin{tabular}{|c|c|c|c|}
\hline \multirow{2}{*}{ Base material } & $\mathbf{R}_{\mathbf{p} 0.2}$ & $\mathbf{R}_{\mathbf{m}}$ & $\mathbf{A}_{\mathbf{5}}$ \\
\cline { 2 - 4 } & \multicolumn{2}{|c|}{$\mathbf{M P a}$} & $\%$ \\
\hline S700MC & 733 & 809 & 19 \\
\hline
\end{tabular}

As it can be seen in Table 3, the strength and deformation properties of the weldments worsened compared to those of the base metal.

Table 3 Tensile testing results of the weldments

\begin{tabular}{|c|c|c|c|c|c|c|}
\hline \multirow{3}{*}{$\begin{array}{l}\text { Mode/welding gap, } \\
\text { mm }\end{array}$} & \multirow{2}{*}{$\mathbf{R}_{\mathbf{p} 0.2}$} & \multirow{3}{*}{$\mathbf{R}_{\mathbf{m}}$} & \multirow{3}{*}{$\begin{array}{l}A_{5} \\
\%\end{array}$} & \multicolumn{3}{|c|}{$\begin{array}{l}\text { Reduction in the mechanical proper- } \\
\text { ties of the weldments }\end{array}$} \\
\hline & & & & $\mathbf{R}_{\mathbf{p} 0.2}$ & $\mathbf{R m}$ & $A_{5}$, \\
\hline & MPa & & & \multicolumn{3}{|c|}{$\%$} \\
\hline Mode $1 /$ Welding gap $=0$ & 634 & 748 & 10 & 86.6 & 92.5 & 53 \\
\hline Mode 2 / Welding gap $=4$ & 677 & 761 & 5.1 & 92.4 & 93.6 & 27 \\
\hline Mode $3 /$ Welding gap $=6$ & 676 & 786 & 7.7 & 92.2 & 97.4 & 41 \\
\hline Mode $4 /$ Welding gap $=8$ & 668 & 757 & 6.4 & 89.6 & 93.4 & 34 \\
\hline
\end{tabular}

The reduction in the strength characteristics was not greater than $10 \%$ except for yield strength $R_{p 0.2}$ for the weldment without root gap. The decrease in the elongation after fracture was considerable. It reached up to $27 \%$ (at a root gap of $4 \mathrm{~mm}$ ) of the elongation in a delivery state. The reduction in plasticity was mainly because the plastic deformation was concentrated in the fusion and heat-affected zones, and the fracture occurred before the deformation spread over the base metal.

\subsection{Bend test}

Used here bend test can be classified as a technological test. Following the standard for testing of S700MC (EN 10149-2), a test piece successfully passes the bend test if no fracture is observed after bending on a former with a radius of $2.5 \mathrm{t}\left(\mathrm{t}-\right.$ specimen's thickness) at a bending angle of $90^{\circ}$. The bending angle in our experiments is no less than $130^{\circ}$. After the bend test, the specimen did not show any marks of fracture neither in the root nor in the weld cap.

\subsection{Impact toughness}

Figure 2 shows the macrostructure of the specimens with a root gap of 4,6 and $8 \mathrm{~mm}$. It is visible that the weldment with a welding gap of $4 \mathrm{~mm}$ experienced a complex fracture - part of the fracture occurred at the heat-affected zone, and the other part - at the boundary between the heat-affected zone and the fusion zone. 
At a welding gap of $6 \mathrm{~mm}$, part of the fracture occurred at the boundary between the heat-affected zone and base metal, and some fracture happened at the base metal too.

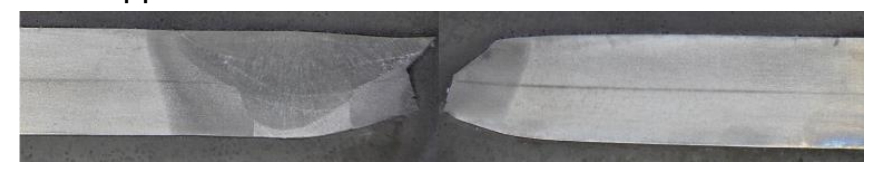

a)

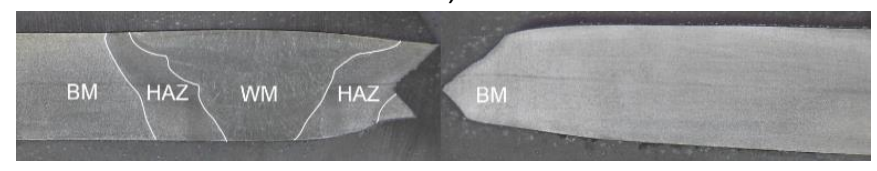

b)

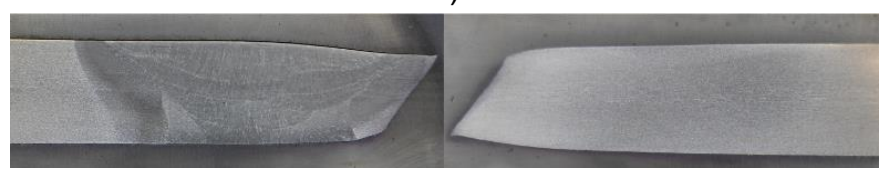

c)

Figure 2 Macrostructure of specimens after tensile test

At a welding gap of $8 \mathrm{~mm}$, the fracture occurred entirely at the boundary between the base metal and the heataffected zone. After the macrostructural observation, notches for the impact toughness testing were made at the fusion zone and the boundary between the heat-affected zone and the base metal, as shown in Figure 3 .

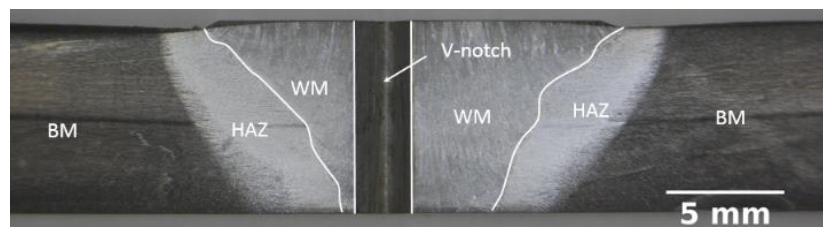

a)

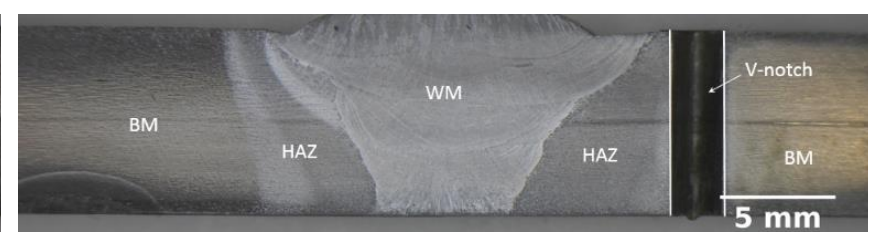

b)

Figure 3 Test piece and location of the V-notch for Charpy pendulum impact test

The averages of the impact toughness values of the specimens in Figure $\mathbf{3}$ are shown in Table 4 . The base metal demonstrated an impact toughness of $270 \mathrm{~J} / \mathrm{cm}^{2}(173 \mathrm{~J} / 0.64)$.

Table 4 Impact toughness values of the weldments

\begin{tabular}{|c|c|c|}
\hline \multirow[t]{2}{*}{ Mode } & \multicolumn{2}{|c|}{ Impact toughness $\mathrm{KV}_{8}\left(-40^{\circ} \mathrm{C}\right), \mathrm{J} / \mathrm{cm}^{2}$} \\
\hline & $\mathbf{F Z}$ & HAZ/BM boundary \\
\hline Welding mode 1 (welding gap $0 \mathrm{~mm}$ ) & 31 & 43 \\
\hline Welding mode 2 (welding gap $4 \mathrm{~mm}$ ) & 38 & 80 \\
\hline Welding mode 3 (welding gap 6 mm) & 28 & 34 \\
\hline Welding mode 4 (welding gap 8 mm) & 33 & 43 \\
\hline
\end{tabular}

The experimentally measured impact toughness values of the weldments indicate a considerable decrease after welding, particularly at the fusion zone. These results were expected given the increased values of the linear energy. Nevertheless, the measured here values of impact toughness agree with the requirements for minimal impact toughness (27 J). 


\section{CONCLUSION}

To meet the increased technical demands posed to welding constructions, more deep research on the factors that affect the behaviour of high strength steels during welding is necessary. There is a lack of information on the effect of the root gap size on the mechanical properties of weldments of high-strength steels, thus research of that kind is a requisite.

The bend test results make evident that the studied here weldments of $700 \mathrm{MC}$ do not demonstrate any signs of fracture, regardless of the welding modes and root gap size.

The fusion zone hardness keeps its high values and is not influenced by the number of welding passes. The hardness of the heat-affected zone increases from $231 \mathrm{HV}$ to $246 \mathrm{HV}$ with the increase in the number of passes. The highest hardness is measured at the base metal and the lowest at the heat-affected zone.

Using welding modes with higher linear energy (more than $1 \mathrm{~kJ} / \mathrm{mm}$ ) leads to an increase in productivity at the expense of a decrease in plasticity $\left(A_{5}\right)$ and impact toughness. The reduction in the strength properties $\left(\mathrm{Rp}_{0.2}\right.$, $\mathrm{R}_{\mathrm{m}}$ ) is not so pronounced and is around $10 \%$.

\section{ACKNOWLEDGEMENTS}

This research was supported by project 2021 - MTF - 01, funded by the Research Fund of the University of Ruse.

\section{REFERENCES}

[1] GÓRKA, J. An influence of welding thermal cycles on properties and HAZ structure of S700MC steel treated using thermomechanical method, In: Scientific Proceedings IX International Congress "Machines, Technologies, Materials". 2012, vol. 3, pp. 41-44.

[2] MRŇA, L., KOPECKÝ, L., NĚMEČEK, T., MIKMEKOVÁ, Š., DOHNAL, I. Laser welding of Domex steel and heterogeneous weld with DC01. In: 22nd International Conference on Metallurgy and Materials. Brno: TANGER, 2013.

[3] MAZUR, M., ULEWICZ, R., NOVY, F., SZATANIAK, P. The structure and mechanical properties of Domex 700MC steel. Communications. 2013, no. 4, pp. 54-57.

[4] ALI, H., ALSULTAN, T. Study the microstructure and impact toughness of welded joints for Weldox 700MC high strength steel. International Journal of Mechanical Engineering and Technology. 2018, vol. 9, pp. 402-408.

[5] KVACKAJ T, BIDULSKÁ J, BIDULSKÝ R., Overview of HSS Steel Grades Development and Study of Reheating Condition Effects on Austenite Grain Size Changes. Materials (Basel). 2021, Apr 15; vol. 14, no. 8, p.1988.

[6] Welding of Strenx. Strenx 700 MC. [online]. 2015. [viewed: 2021-05-23]. Available from: https://www.oxycoupage.com/FichiersPDF/Ssab/English/Strenx/Welding\%20Strenx\%20700\%20MC.pdf.

[7] LISIECKI, A. Welding of thermomechanically rolled steel by Yb: Yag disk laser. Archives of metallurgy and materials. 2015, vol. 60, pp. 2851-2859.

[8] SILVA, A., SZCZUCKA-LASOTA, B., WĘGRZYN, T., JUREK, A. MAG welding of S700MC steel used in transport means with the operation of low arc welding method. Welding Technology Review. 2019, vol. 91, pp. 23-28.

[9] DZYUBYK, A., PALASH, V., KHOMYCH, I., HRYNUS, S. Optimization of welding modes for high-strength lowalloy Domex 700 steel. Ukrainian Journal of Mechanical Engineering and Materials Science. 2017, vol. 3, no. 2, pp. 47-54.

[10] FERDINANDOV, N., GOSPODINOV, D., ILIEVA, M., RADEV, R. Effect of the Root Gap on the Structure and Properties of High Strength Steel S700MC Welds. Key Engineering Materials. 2020, vol. 890, pp. 201-208.

[11] KŘíŽ, A., ZAJÍČEK, M. Impact of welding process on mechanical properties of Domex 700MC steel and comparison of welded joint of S355NJ structural steel, In: 20th International Conference on Metallurgy and Materials. Ostrava: TANGER, 2011. 